\title{
The Impact of Vibration on the Technological Head
}

Anton Panda ${ }^{1}$, Marek Prislupčák ${ }^{1}$, Jozef Jurko ${ }^{1}$, Iveta Pandová ${ }^{1}$, Ivan Mrkvica ${ }^{2}$, Slawomir Luscinski ${ }^{3}$

${ }^{1}$ Faculty of Manufacturing Technologies with a seat in Prešov, The Technical University of Košice, Štúrová 31,08001

Prešov, Slovakia. E-mail: anton.panda@tuke.sk, marek.prislupcak@tuke.sk,jozef.jurko@tuke.sk, iveta.pan-

dova@tuke.sk

${ }^{2}$ VSB-Technical University of Ostrava, Faculty of Mechanical Engineering, Department of Machining Assembly and Manufacturing Technology, 17. Listopadu 15, 70833 Ostrava, Czech Republic. E-mail: ivan.mrkvica@vsb.cz

${ }^{3}$ Politechnika Swietokrzyska, Kielce University of Technology, al. Tysiąclecia Państwa Polskiego 7, 25-314 Kielce, Poland. E-mail: luscinski@tu.kielce.pl

The aim of the measurement was the observation (examination) and evaluation of the vibration impact on the technological head in the technology of abrasive water jet when changing the selected technological parameters, namely the feed rate of the technological head. The experiments were carried out on one kind of material - steel HARDOX 500 with a thickness of $10 \mathrm{~mm}$. The impact of the change of the technological head's feed rate (400, $200,100,50,40 \mathrm{~mm} / \mathrm{min}$ ) on the size of the vibration acceleration amplitude and its frequency were examined. A database was created from the measured vibration values on the technological head and from that database the data was evaluated in selected softwares (LabVIEW, SignalExpress a Microsoft Excel). Graphical dependencies, frequency spectra covers and covers comparison graph were created from which new findings and conclusions were formulated.

Keywords: Hydroabrasive water flow, technological head, vibration, vibration acceleration amplitude, frequency.

\section{Acknowledgement}

The authors would like to thank the VEGA and KEGA grant agency for supporting research work and co-financing the project VEGA 1/0409/13 and KEGA 027 TUKE - 4/2014.

\section{References}

[1] KRAJNÝ, Z. (1998). Vodný lúč v praxi, pp. 30, Miroslav Mračko, Bratislava, Slovak Republic.

[2] MANKOVÁ, I. (2000). Progresívne technológie. pp. 275, Košice : Technická univerzita Košice, Strojnícka fakulta - edícia vedeckej a odbornej literatúry, Slovak Rep.

[3] HLOCH, S., VALÍČEK, J. (2008). Vplyv faktorov na topografiu povrchov vytvorených hydroabrazívnym delením. Fakulta výrobných technológií TU v Košiciach so sídlom v Prešove.

[4] VALÍCEK, J., HLOCH, S. (2008). Merení a rízení kvality povrchu vytvorených hydroabrazivním delením. 1. Vydání, pp. 128, Ostrava: ÁMOS Mgr. Zdenka Pustinová, Czech Rep.

[5] VASILKO, K. (2007). Analytická teória trieskového obrábania. pp. 338, Prešov Fakulta výrobných technologií TU v Košiciach, Slovak Rep.

[6] HUMÁR, A. (2004). Technologie I.: Technologie obrábení - 2. cást [online]. Brno : Vysoké ucení technické v Brne, Fakulta strojního inženýrství, [cit. 2012-09-25]. 〈http://ust.fme.vutbr.cz/obrabeni/?page=opory>.

[7] Návrh špeciálneho anténneho rotárora [on-line]. [cit 2012-11-20]. <http://www.vutbr.cz/www_base/zav_prace_soubor_verejne.php?file_id=26768>

[8] Konvenčné obrábanie [on-line]. [cit 2012-11-05]. <http://www.poziadavka.sk/ponuky/ponuka-57638/Konvencneobrabanie>

[9] Nekonvenčné metódy obrábania [on-line]. [cit 2012-10-07]. http://www.tuzvo.sk/files/FEVT/katedry_fevt/kvtm/nmo_obr.pdf

[10] SALOKYOVÁ, Š. (2011). Návrh metód a technických systémov (hardvér a softvér) pre elimináciu vibrácií a hlučnosti s aplikáciou na výrobné systémy s vybranými druhmi technológie. Písomný materiál k dizertačnej práci. 08.04.2011. Prešov, Slovak Rep.

[11] PRISLUPČÁK, M. (2013). Skúmanie vplyvu rezných parametrov na vznik vibrácií technologickej hlavice vo výrobnom systéme s technológiou AWJ. Diplomová práca. 62 s. Prešov

[12] LATTNER, M., HOLESOVSKY, F. (2014). Effect of machining the load capacity notched components, Manufacturing Technoogy, Czech Rep. 
[13] HOLESOVSKY, F., NOVAK, M., LATTNER, M., VYSLOUZIL, T. (2014). Effect of machining the load capacity notched components. In: Key Engineering Materials, Zurich, Switzerland.

[14] HOLESOVSKY, F., NAPRSTKOVA, N., NOVAK, M. (2012). GICS for Grinding Process Optimization. In: Manufacturing Technology, Vol. 12, No. 12, pp. 22-26, J. E. Purkyne University in Usti nad Labem, Czech Republic.

[15] ZELENAK, M., VALICEK, J., HLOCH, S., KOZAK, D., SAMARDZIC, I., HARNICAROVA, M., KLICH, J., HLAVACEK, P., CINCIO, R. (2012). Comparison of mechanical properties of surface layers with use of nanoindentation and microindentation tests. In: Metalurgija 51(3): 309-312, Croatia.

Copyright @ 2016 . Published by Manufacturing Technology. All rights reserved. 